\title{
Health-related quality of life after successful surgery for primary hyperparathyroidism: no additive effect from vitamin $D$ supplementation: results of a double-blind randomized study
}

\author{
Viveca Åberg, Sophie Norenstedt, Jan Zedenius, Maria Sääf, Jörgen Nordenström, \\ Ylva Pernow and Inga-Lena Nilsson \\ Department of Breast and Endocrine Surgery, Karolinska University Hospital, P9:03, SE-171 76 Stockholm, Sweden
}

Correspondence should be addressed to I-L Nilsson

Email

inga-lena.nilsson@ki.se

\begin{abstract}
Objective: Vitamin D insufficiency is common in primary hyperparathyroidism (pHPT). Patients with pHPT frequently have a reduced health-related quality of life (HRQoL). Our objectives were to evaluate whether HRQoL in pHPT is associated with vitamin D insufficiency and whether vitamin D supplementation after parathyroidectomy (PTX) could improve HRQoL. Design: A randomized, double-blind study (ClinicalTrials.gov identifier: NCT00982722).

Methods: The study included 150 pHPT patients randomized, 6 weeks after PTX, to daily treatment with either cholecalciferol $1600 \mathrm{IU}$ and calcium carbonate $1000 \mathrm{mg}(\mathrm{D}+)$ or calcium carbonate alone (D-). HRQoL was estimated with SF-36 before and after PTX and after 12 months of study medication.

Results: Three-quarters (77\%) of the pHPT patients had vitamin D insufficiency, defined as $250 H \mathrm{D}<50 \mathrm{nmol} / \mathrm{l}$. The pHPT patients scored lower than a reference population in all domains of SF-36. A total of 135 patients completed the entire study period. Improvements in nearly all domains were registered at the follow-up 6 weeks after PTX. At the end of the study medication period, the $D+$ group had a significantly higher median serum (s-) 25OHD concentration (76 (65; 93) (lower; upper interquartile ranges) vs $48(40 ; 62) \mathrm{nmol} / \mathrm{l}, P<0.001)$ and a lower plasma (p-) parathyroid hormone concentration $(40(34 ; 52)$ vs $49(38 ; 66) \mathrm{ng} / \mathrm{l}, P=0.01)$ than the $\mathrm{D}$ - group. The improvements in HRQoL remained unchanged at the follow-up 1 year after PTX. Postoperative vitamin D supplementation had no obvious effect on HRQoL.

Conclusion: PTX resulted in significant improvements in HRQoL. Despite a high prevalence of vitamin D insufficiency, 1 year of postoperative vitamin D supplementation had no obvious beneficial effect on HRQoL.
\end{abstract}

\section{Introduction}

Primary hyperparathyroidism (pHPT) is a common endocrine disorder, characterized by an inappropriately high secretion of parathyroid hormone (PTH) from one or more of the parathyroid glands, causing an elevated plasma concentration of calcium. The incidence increases with age (1). Neurocognitive symptoms, depression, and impairment of health-related quality of life (HRQoL) are overrepresented in pHPT (2). Successful parathyroidectomy (PTX) has been associated with improvements in HRQoL, but the reported results are not consistent $(2,3,4,5,6,7,8)$. Based on the recent guidelines, data indicating a predictable improvement are still not sufficient to recommend PTX on the basis of these symptoms (2). (c) 2015 The authors Published by Bioscientifica Ltd

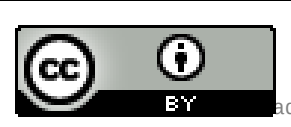

This work is licensed under a Creative Commons Attribution 3.0 Unported License. 
Vitamin D insufficiency is more frequent in patients with pHPT than in the general population, but its prevalence differs between $\mathrm{pHPT}$ populations $(9,10,11,12)$. Vitamin D is important for calcium homeostasis and a poor vitamin D status may influence the severity of pHPT (12). Vitamin D deficiency has been associated with declining cognitive and physical functions and mood disorders, but the results of interventional studies on the effects of vitamin D supplementation have not been convincing (13).

The international guidelines for the management of asymptomatic pHPT recommend supplementation of vitamin $\mathrm{D}$ when the serum concentration of $25 \mathrm{OHD}$ is below $50 \mathrm{nmol} / 1$ (14). Judicious vitamin D supplementation has been reported to safely improve vitamin D status and decrease PTH in pHPT patients without increasing the calcium concentration in plasma or urine (15). Still questions remain about the effects of vitamin D supplementation in pHPT. The aim of this study was to evaluate the relation between vitamin $\mathrm{D}$ status and HRQoL and the effects of postoperative vitamin D supplementation on health recovery.

\section{Materials and methods}

Between April 2008 and January 2011, 159 consecutive pHPT patients subjected to PTX were recruited in a doubleblinded, randomized clinical trial. The study cohort has been described in detail in two previous publications $(16,17)$. After successful PTX, 150 patients with $\mathrm{pHPT}$ were randomized, 75 patients in each group, to 1-year treatment with either calcium carbonate $500 \mathrm{mg} / 800 \mathrm{IU}$ cholecalciferol $\times 2$ daily ( $\mathrm{D}+$ group) or calcium carbonate $500 \mathrm{mg} \times 2$ daily (D- group) (Fig. 1). Recip AB (Stockholm, Sweden) delivered the specifically prepared study medication. The measurements were repeated 6 weeks before PTX, at randomization 6 weeks after PTX, and after 6 and 12 months of study medication. A safety control of the calcium and creatinine concentrations and the tolerability of the medication were performed after 6 weeks of study medication. Blood samples were drawn after an overnight fasting. Body weight and height were measured and BMI was calculated as weight $(\mathrm{kg})$ divided by the square of height $(\mathrm{m})$. The cohort size was determined by power calculation based on the expected drop in plasma PTH concentration $(16,17)$. The study population, comprising 135 patients who completed all four surveys (SF-36), was compared with a reference cohort of 459 age- and sex-matched individuals, randomly drawn from the Swedish SF-36 national normative database $(n=8930)$ (18). A total of 135 patients completed the

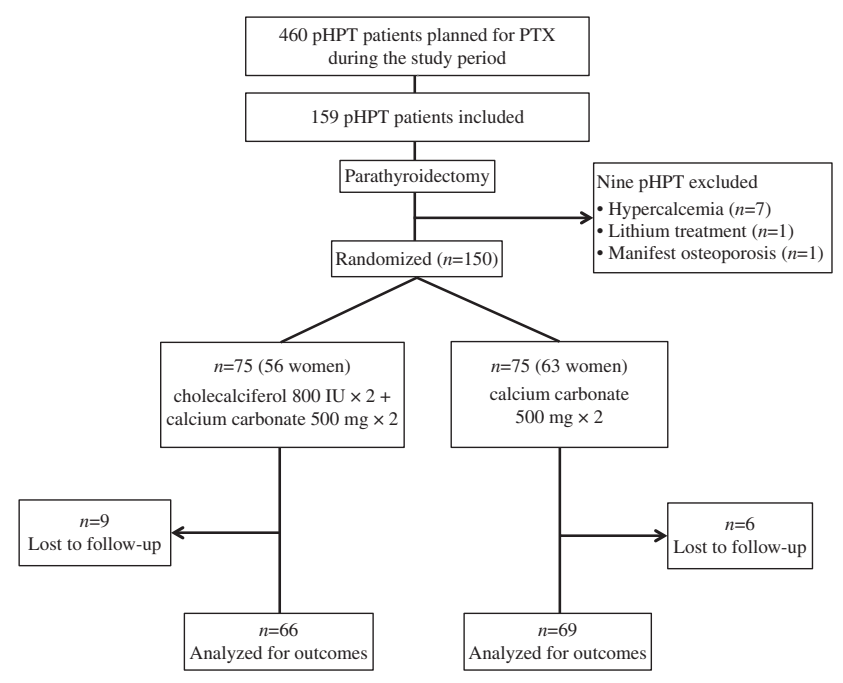

Figure 1

Flowchart of the study.

entire 1-year study period after randomization and these patients were included in the final analysis of HRQoL. Clinical characteristics did not differ between dropouts and those who completed the study $(16,17)$. The study was approved by the Medical Products Agency and by the local Ethics Committee.

\section{Laboratory methods}

Plasma concentrations of total calcium were measured using the Synchron LX 20 System (Beckman Coulter, Inc., Brea, CA, USA). Serum ionized calcium $\mathrm{Ca}^{2+}$ was analyzed on ABL 800 (Radiometer, Copenhagen, Denmark). Plasma concentrations of intact PTH were determined using the electrochemiluminescence immunoassay on the Modular E system (Roche Diagnostics GmbH). Serum concentrations of $25 \mathrm{OHD}$ were measured by chemiluminescence on Liason XL (DiaSorin, Inc., Stillwater, MN, USA); the interassay coefficient of percentage variation (\%CV) is $4.6 \%$ at $15.5 \mathrm{nmol} / \mathrm{l}$ and $2.7 \%$ at $68.3 \mathrm{nmol} / \mathrm{l}$ and intraassay $\% \mathrm{CV}$ is $4.4 \%$ at $15.5 \mathrm{nmol} / \mathrm{l}$ and $2.6 \%$ at $68.3 \mathrm{nmol} / \mathrm{l}$. In order to minimize the interassay variation, the preoperative and postoperative samples of $25 \mathrm{OHD}$ were analyzed in the same series on serum previously frozen at $-70^{\circ} \mathrm{C}$. Values below $50 \mathrm{nmol} / \mathrm{l}$ were considered to represent vitamin D insufficiency $(19,20)$.

\section{Quality-of-life measurements}

The SF-36 Healthy Survey, version 2.0 containing 36 questions, has proven reliable and valid in various 
groups (18). Individual answers are compiled to create eight scales, of which four (Physical Functioning, Role Physical, Bodily Pain, and General Health (GH)) are measurements of physical health and the remaining four (Vitality, Social Functioning (SF), Role Emotional, and Mental Health) are indicative of mental well-being in the last 4 weeks. The combination of all eight scales constructs two composite scales: the Physical Component Summary (PCS) and the mental component summary. All scales are standardized from 0 to 100 , with higher scores signifying better health status.

\section{Statistical analyses}

All analyses were performed using the SPSS version 22 . Data, since not normally distributed, were analyzed by nonparametric tests. For comparisons between groups, the Mann-Whitney $U$ test for unpaired data was used. KruskalWallis one-way ANOVA was used for comparisons with respect to independent categorical variables with more than two levels. For paired analyses, the Wilcoxon's signed rank sum test was used. The scores are presented as median and interquartile range (IQR). $\chi^{2}$ test was used for the analysis of distribution of categorical variables. Relationships between variables were assessed with Spearman's $P$ correlation test. All tests were done two tailed and $P<0.05$ was considered to be statistically significant.

\section{Results}

A total of 135 patients completed the study period. Vitamin D deficiency, defined as s-25OHD $<50 \mathrm{nmol} / \mathrm{l}$, was present in about three-quarters of the patients. The characteristics of the pHPT patients are presented in Table 1 . Table 2 presents the SF-36 scores of the reference cohort and of the pHPT patients pre-surgery (baseline), 6 weeks after surgery (the time for randomization to study medication), and after 1 year of treatment. The patients scored significantly lower than the reference population in all eight domains and the two component scales of the SF-36. No correlation was found between SF-36 scores and the concentrations of ionized calcium or p-PTH (data not shown). The baseline HRQoL estimated with SF-36 did not differ between different s-25OHD-quartiles (Table 3).

A single parathyroid adenoma was removed in nearly all cases (132/135); the median adenoma weight was $0.455 \mathrm{~g}$ (range 0.075-27.800 g). At follow-up 6 weeks after PTX, the calcium level was normalized in all cases, but the p-PTH concentration was elevated above the normal upper limit of $65 \mathrm{ng} / \mathrm{l}$ in $50 \%$ of the cases. The s-25OHD was
Table 1 Clinical characteristics at baseline for patients analyzed for outcomes $(n=135)$.

Age, years, median (minimum-maximum)

Females/males

$62(30-80)$

$109 / 26$

BMI $\left(\mathrm{kg} / \mathrm{m}^{2}\right)$, median (minimum-maximum)

Weight of adenoma $(\mathrm{mg})$ median

(minimum-maximum)

Vitamin $\mathrm{D}<50 \mathrm{nmol} / \mathrm{l}, n(\%)$

Diabetes $(n)$

Antihypertensive treatment $(n)$

Osteoporosis $(n)$

Smokers $(n)$

$\mathrm{S}-\mathrm{Ca}^{2+}(1.15-1.33 \mathrm{mmol} / \mathrm{l}$, median (IQR))

p-PTH (10-65 ng/l, median (IQR))

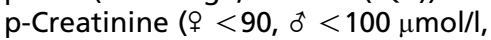
median (IQR))

$26.0(17.1-43.4)$

$455(75-27800)$

$104(77 \%)$

\section{5}

\section{9}

62

20

$1.43(1.38 ; 1.47)$

$116(89 ; 148)$

$65(56 ; 76)$

higher compared with baseline $(41(33 ; 54)$ vs $40(31 ; 49)$ nmol/l; $P=0.005)$. Vitamin D insufficiency, defined as $\mathrm{s}-25 \mathrm{OHD}$ below $50 \mathrm{nmol} / \mathrm{l}$, was present in $66 \%$ of the patients. The pHPT cohort improved their scores in all except one domain ('Role Physical'; Table 2). At the start of the study medication period, the $\mathrm{s}-25 \mathrm{OHD}$ concentration was similar in the two groups $(40(33 ; 53)$ in $\mathrm{D}+$ and $45(35 ; 54) \mathrm{nmol} / \mathrm{l}$ in $\mathrm{D}-; P=0.247)$. The medication was well tolerated and the s-ionized calcium, p-phosphate, p-creatinine, and the urinary calcium concentrations remained unchanged during the study period. In both the $\mathrm{D}+$ and the $\mathrm{D}-$ group, no significant changes in the SF-36 scores were observed during the entire period of study medication (Table 4). At the end of the study medication period, the $\mathrm{D}+$ group had significantly higher s-25OHD (76 (65; 93) vs $48(40 ; 62) \mathrm{nmol} / \mathrm{l} ; P<0.001)$ and lower p-PTH $(40(34 ; 52)$ vs $49(38 ; 66) \mathrm{ng} / \mathrm{l} ; P=0.01)$. No significant differences in the SF-36 scores between the groups were observed. The pHPT cohort reached the level of the reference population in one domain of SF-36, GH, and in one composite score, PCS (Table 2).

\section{Discussion}

The main results of this double-blinded randomized trial were that vitamin D supplementation after successful PTX resulted in higher s-25OHD and lower p-PTH concentrations but had no obvious beneficial effect on HRQoL despite a high prevalence of vitamin $\mathrm{D}$ insufficiency in the pHPT cohort.

As shown previously in both observational and randomized studies, pHPT patients express impaired HRQoL. Vitamin D insufficiency is overrepresented in pHPT and may contribute to neuropsychiatric symptoms (21). 
Table 2 SF-36 QoL score in a reference population and in pHPT patients who completed the study period pre-surgery, at randomization (post-surgery) and after 12-month medication in both groups.

\begin{tabular}{|c|c|c|c|c|c|c|c|c|c|c|c|c|}
\hline \multirow[b]{2}{*}{ SF-36 } & \multicolumn{2}{|c|}{$\begin{array}{l}\text { Reference } \\
\text { population }\end{array}$} & \multicolumn{2}{|c|}{$\begin{array}{l}\text { Pre-surgery } \\
\quad(n=135)\end{array}$} & \multicolumn{2}{|c|}{$\begin{array}{c}\text { Post-surgery } \\
\quad(n=135)\end{array}$} & \multicolumn{2}{|c|}{$\begin{array}{c}12 \text { months } \\
(n=135)\end{array}$} & \multirow[b]{2}{*}{$\boldsymbol{P}^{\mathrm{a}}$} & \multirow[b]{2}{*}{$\boldsymbol{P}^{\mathrm{b}}$} & \multirow[b]{2}{*}{$\boldsymbol{P}^{c}$} & \multirow[b]{2}{*}{$\boldsymbol{P}^{\mathrm{d}}$} \\
\hline & Median & IQR & Median & $\mathrm{IQR}$ & Median & IQR & Median & IQR & & & & \\
\hline Physical Function (PF) & 85 & $85-90$ & 80 & $61-95$ & 85 & $70-95$ & 85 & $65-95$ & $<0.001$ & 0.003 & $<0.001$ & 0.428 \\
\hline Role Physical (RP) & 100 & $100-100$ & 75 & $25-100$ & 100 & $25-100$ & 100 & $50-100$ & $<0.001$ & 0.211 & $<0.001$ & 0.168 \\
\hline Bodily Pain (BP) & 72 & $72-100$ & 62 & $41-100$ & 74 & $41-100$ & 72 & $42-100$ & $<0.001$ & 0.006 & 0.036 & 0.211 \\
\hline General Health (GH) & 76 & $75-76$ & 67 & $47-82$ & 72 & $60-87$ & 72 & $57-91$ & $<0.001$ & $<0.001$ & 0.924 & 0.672 \\
\hline Vitality (VT) & 75 & $75-80$ & 50 & $30-70$ & 65 & $45-80$ & 65 & $45-80$ & $<0.001$ & $<0.001$ & $<0.001$ & 0.596 \\
\hline Social Functioning (SF) & 100 & $100-100$ & 75 & $50-100$ & 88 & $63-100$ & 100 & $75-100$ & $<0.001$ & $<0.001$ & $<0.001$ & 0.225 \\
\hline Role Emotional (RE) & 100 & $100-100$ & 67 & $0-100$ & 100 & $33-100$ & 100 & $67-100$ & $<0.001$ & $<0.001$ & $<0.001$ & 0.173 \\
\hline Mental Health (MH) & 88 & 84-92 & 72 & $52-88$ & 84 & 64-92 & 82 & $68-92$ & $<0.001$ & $<0.001$ & $<0.001$ & 0.915 \\
\hline $\begin{array}{l}\text { Physical Component } \\
\text { Summary }\end{array}$ & 48 & $48-51$ & 47 & $38-54$ & 48 & $40-55$ & 49 & $40-55$ & 0.001 & 0.039 & 0.186 & 0.708 \\
\hline $\begin{array}{l}\text { Mental Component } \\
\text { Summary }\end{array}$ & 50 & $53-55$ & 42 & $29-53$ & 50 & $40-56$ & 52 & $42-57$ & $<0.001$ & $<0.001$ & $<0.001$ & 0.121 \\
\hline
\end{tabular}

IQR, inter quartile range; Wilcoxon's signed rank sum test, paired data.

apre-surgery vs reference population.

${ }^{\mathrm{b}}$ Randomization (post-surgery) vs pre-surgery.

'One year of treatment vs reference population.

${ }^{\mathrm{d}}$ One year of treatment vs randomization (post-surgery).

In a recent meta-analysis of population-based epidemiological studies that included more than 50000 study participants, an inverse association has been demonstrated between serum 25OHD and the risk of depression. Based on a meta-analysis, an increase in $25 \mathrm{OHD}$ of $25 \mathrm{nmol} / \mathrm{l}$ was associated with an $8 \%$ decrease in the incidence of depression (22). We used the SF-36 score for estimation of HRQoL. This protocol is well validated and allows comparison between patients and the background population. Our pHPT patient cohort scored significantly worse in all domains than the reference population $(18,23)$. Major improvements were registered postoperatively, above ten units in most domains, often recommended as the least significant change (2). However, except for a correlation between baseline s-25OHD and the domain 'Mental Health', we found no correlation between vitamin D status and HRQoL. The minor increase in s-25OHD after PTX confirms earlier findings (10).

The exact mechanism of this increase has not been clarified (13). Theoretically, the postoperative reduction in PTH will result in reduced activation of $25 \mathrm{OHD}$ to $1,25(\mathrm{OH})_{2} \mathrm{D}$ and thereby decreased rate of metabolic clearance (24). In line with other reports, we observed no

Table 3 Baseline clinical characteristics, biochemistry, and HRQoL in different vitamin $D$ quartiles. Mann-Whitney $U$ test for unpaired data. Kruskal-Wallis test for unpaired data.

\begin{tabular}{|c|c|c|c|c|c|c|c|c|}
\hline \multirow[b]{3}{*}{ SF-36 } & \multicolumn{2}{|c|}{ I $(n=29(259))$} & \multicolumn{2}{|c|}{ II- III $(n=75(60 q))$} & \multicolumn{2}{|c|}{ IV $(n=31(24 \%))$} & \multirow[b]{3}{*}{$\boldsymbol{P}(\mathrm{I}-\mathrm{II}-\mathrm{III})$} & \multirow[b]{3}{*}{$\boldsymbol{P}(I-(I I+I I I))$} \\
\hline & \multicolumn{2}{|c|}{$<31 \mathrm{~s}-25 \mathrm{OH}$ vit $\mathrm{D}$} & \multicolumn{2}{|c|}{$>31 \mathrm{~s}-25 \mathrm{OH}$ vit $\mathrm{D}<50$} & \multicolumn{2}{|c|}{$>50 \mathrm{~s}-25 \mathrm{OH}$ vit $\mathrm{D}$} & & \\
\hline & Median & IQR & Median & IQR & Median & IQR & & \\
\hline Physical Function (PF) & 75 & $50 ; 90$ & 80 & $70 ; 95$ & 80 & $64 ; 95$ & 0.284 & 0.113 \\
\hline Role Physical (RP) & 75 & $25 ; 100$ & 100 & $25 ; 100$ & 100 & $19 ; 100$ & 0.531 & 0.272 \\
\hline Bodily Pain (BP) & 62 & $36 ; 92$ & 62 & $41 ; 100$ & 57 & $41 ; 100$ & 0.744 & 0.471 \\
\hline General Health (GH) & 65 & $45 ; 77$ & 65 & $47 ; 81$ & 72 & $55 ; 87$ & 0.516 & 0.323 \\
\hline Vitality (VT) & 50 & $30 ; 66$ & 53 & $30 ; 70$ & 48 & $30 ; 75$ & 0.759 & 0.465 \\
\hline Social Functioning (SF) & 75 & $50 ; 100$ & 75 & $50 ; 100$ & 81 & $50 ; 100$ & 0.615 & 0.342 \\
\hline Role Emotional (RE) & 67 & $0 ; 100$ & 67 & $0 ; 100$ & 100 & $33 ; 100$ & 0.519 & 0.809 \\
\hline Mental Health (MH) & 70 & $44 ; 82$ & 74 & $52 ; 88$ & 72 & $59 ; 89$ & 0.192 & 0.083 \\
\hline Physical Component Summary & 43 & $34 ; 54$ & 48 & $40 ; 54$ & 47 & $37 ; 55$ & 0.584 & 0.300 \\
\hline Mental Component Summary & 41 & $32 ; 52$ & 43 & $29 ; 54$ & 41 & $35 ; 54$ & 0.666 & 0.486 \\
\hline
\end{tabular}

$\mathrm{IQR}$, inter quartile range. 


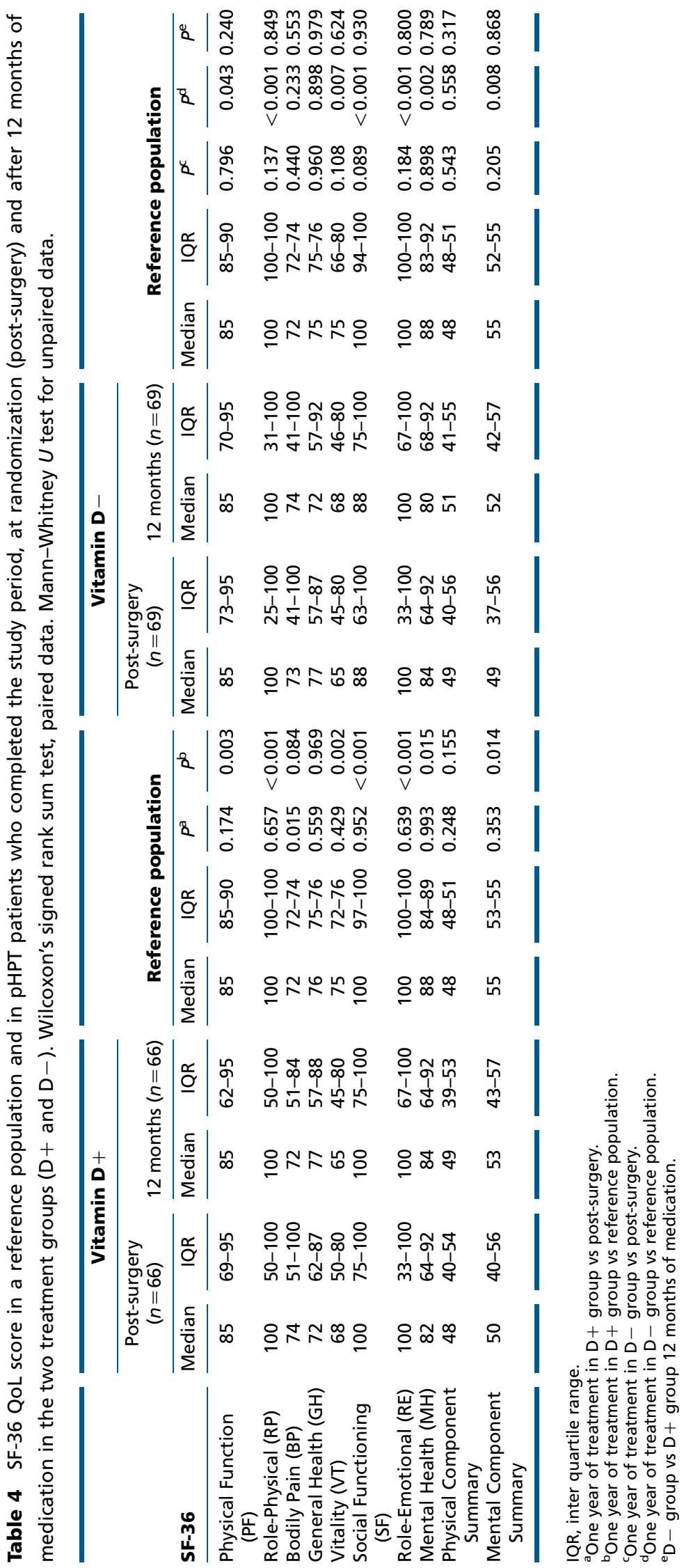


correlation between SF-36 scores and PTH concentration or the extent of hypercalcemia (4). Improvements in HRQoL after PTX have been reported from many different studies, but studies on long-term effects have yielded inconsistent results $(3,4,5,6,7,8)$. A placebo-effect of surgery must always be considered. However, since the improvements in HRQoL remained 1 year after surgery, we consider this less likely. Only exceptionally did the patients reach the levels of the reference population. Possibly, the common coexistence of other disorders, such as hypertension, in the cohort may have contributed to the residual reduction. Judicious replacement of vitamin D in pHPT patients has been reported to be safe, provided the patients are followed closely (15). In our cohort of pHPT patients, vitamin D insufficiency was frequent and equally distributed between the groups at randomization. During 12-month study medication, no changes in SF-36 scores were observed in the $\mathrm{D}+$ and $\mathrm{D}-$ groups. The SF-36 scores did not differ between the two groups, either at the beginning or at the end of the study medication period, but the $\mathrm{D}+$ group had higher s-25OHD and lower p-PTH levels. We cannot exclude the possibility that the lower PTH level in the D+ group may have beneficial effects in the long run. The optimal cut-off for vitamin D insufficiency is still controversial. The international guidelines from 2009 recommend measurement of $25 \mathrm{OHD}$ in all patients and repletion is recommended when the vitamin $\mathrm{D}$ level is below $50 \mathrm{nmol} / \mathrm{l}$ (14). Vitamin D insufficiency may be present even with vitamin D levels above $50 \mathrm{nmol} / 1$. Based on a recent report, p-PTH levels continue to decline even when s-25OHD levels increase above $75 \mathrm{nmol} / \mathrm{l}$ (25).

The strength of this study is the randomized and double-blinded design. The study has some limitations. The SF-36 may be less sensitive for detecting subtle changes than a disease-specific protocol. However, disease-specific questionnaires such as Pasieka's parathyroid symptoms score correlate well with SF-36 (26). We cannot exclude the possibility that the daily supplementation of $1000 \mathrm{mg}$ calcium carbonate instead of placebo may have interfered with the results. We also have to consider the risk of type 2 errors because the cohort size was determined by power calculation based on the expected drop in plasma PTH, not on the variables estimating HRQoL. Neither can we rule that a higher dose of vitamin $\mathrm{D}$ or a longer period with study medication would have affected the outcome. Ten percent of the study cohort was lost to follow-up. We have to be aware of the risk that the incomplete follow-up may bias the results. However, the clinical characteristics did not differ between dropouts and those who completed the study and the number of drop-outs was similar in the two groups.

In conclusion, this study confirms that successful PTX results in significant improvements in HRQoL. Our findings do not support the assumption that vitamin D insufficiency contributes to impaired HRQoL in pHPT. Postoperative vitamin D supplementation resulted in higher s-25OHD and lower PTH. Despite a high prevalence of vitamin D insufficiency, we observed no additive effect from vitamin D supplementation on the aspects of HRQoL.

\section{Declaration of interest}

The authors declare that there is no conflict of interest that could be perceived as prejudicing the impartiality of the research reported.

\section{Funding}

Recip $A B$ provided the study medication but were not involved in the design, conduction, implementation, data analysis or manuscript writing.

\section{Author contribution statement}

S Norenstedt, Y Pernow, J Zedenius, J Nordenström, M Sääf, and I-L Nilsson were involved in sudy design; V Åberg, S Norenstedt, Y Pernow, J Zedenius, J Nordenström, M Sääf, I-L Nilsson conducted the study; V Åberg, S Norenstedt, Y Pernow, J Zedenius, J Nordenström, M Sääf, I-L Nilsson involved in data collection; $\mathrm{V}$ Åberg and I-L Nilsson. Data interpretation: V Åberg, S Norenstedt, Y Pernow, J Zedenius, J Nordenström, M Sääf, and I-L Nilsson analyzed data. $V$ Åberg, I-L Nilsson, $Y$ Pernow were involved in drafting the manuscript; $V$ Åberg, S Norenstedt, Y Pernow, J Zedenius, J Nordenström, M Sääf, and I-L Nilsson reveiwed the manuscript; V Åberg, S Norenstedt, Y Pernow, J Zedenius, J Nordenström, M Sääf, and I-L Nilsson approved the final version of manuscript; I-L Nilsson takes responsibility for the integrity of the data analysis.

\section{Acknowledgements}

The authors would like to express our sincere gratitude to the research nurses Agneta Eriksson, and L Ånfalk for taking care of the patients in a professional manner. They also thank all other staff members who contributed to the study.

\section{References}

1 Fraser WS. Hyperparathyroidism. Lancet 2009374 145-158. (doi:10. 1016/S0140-6736(09)60507-9)

2 Silverberg SJ, Clarke BL, Peacock M, Bandeira F, Boutroy S, Cusano NE, Dempster D, Lewiecki EM, Liu JM, Minisola S et al. Current issues in the presentation of asymptomatic primary hyperparathyroidism: proceedings of the fourth international workshop. Journal of Clinical Endocrinology and Metabolism 201499 3580-3594. (doi:10.1210/jc.2014-1415)

3 Talpos GB, Bone HG III, Kleerekoper M, Philips ER, Alam M, Honasoge M, Divine GW \& Rao DS. Randomized trial of parathyroidectomy in mild asymptomatic primary hyperparathyroidism: patient description and effects on the SF-36 health survey. Surgery 2000128 1013-1020. (doi:10.1067/msy.2000.110844) 
4 Pasieka JL, Parsons L \& Jones J. The long-term benefit of parathyroidectomy in primary hyperparathyroidism: a 10-year prospective surgical outcome study. Surgery 2009146 1006-1013. (doi:10.1016/ j.surg.2009.10.021)

5 Caillard C, Sebag F, Mathonnet M, Gibelin H, Brunaud L, Loudot C, Kraimps JL, Hamy A, Bresler L, Charbonnel B et al. Prospective evaluation of quality of life (SF-36v2) and nonspecific symptoms before and after cure of primary hyperparathyroidism (1-year follow up). Surgery 2007141 153-159. (doi:10.1016/j.surg.2006.12.004)

6 Bollerslev J, Jansson S, Mollerup CL, Nordenström J, Lundgren E, Tørring O, Varhaug JE, Baranowski M, Aanderud S, Franco C et al. Medical observation compared to parathyroidectomy for asymptomatic primary hyperparathyroidism: a prospective, randomized trial. Journal of Clinical Endocrinology and Metabolism 200792 1687-1692. (doi:10.1210/jc.2006-1836)

7 Weber T, Eberle J, Messelhäuser U, Schiffmann L, Nies C, Schabram J, Zielke A, Holzer K, Rottler E, Henne-Bruns D et al. Parathyroidectomy, elevated depression scores, and suicidal ideation in patients with primary hyperparathyroidism: results of a prospective multicenter study. JAMA Surgery 2013148 109-115. (doi:10.1001/2013.jamasurg.316)

8 Walker MD, McMahon DJ, Inabnet WB, Lazar RM, Brown I, Vardy S, Cosman F \& Silverberg SJ. Neuropsychological features in primary hyperparathyroidism: a prospective study. Journal of Clinical Endocrinology and Metabolism 200994 1951-1958. (doi:10.1210/jc.2008-2574)

9 Moosgaard B, Vestergaard P, Heickendorff L, Melsen F, Christiansen P \& Mosekilde L. Vitamin D status, seasonal variations, parathyroid adenoma weight and bone mineral density in primary hyperparathyroidism. Clinical Endocrinology 200563 506-513. (doi:10.1111/j.13652265.2005.02371.x)

10 Farahnak P, Lärfars G, Sten-Linder M \& Nilsson IL. Mild primary hyperparathyroidism: vitamin D deficiency and cardiovascular risk markers. Journal of Clinical Endocrinology and Metabolism 201196 2112-2118. (doi:10.1210/jc.2011-0238)

11 Norman J, Goodman A \& Politz D. Calcium, parathyroid hormone, and vitamin $D$ in patients with primary hyperparathyroidism: normograms developed from 10,000 cases. Endocrine Practice 201117 384-394. (doi:10.4158/EP09346.OR)

12 Silverberg SJ. Vitamin D deficiency and primary hyperparathyroidism. Journal of Bone and Mineral Research 200722 (Suppl 2) V100-V104. (doi:10.1359/jbmr.07s202)

13 Autier P, Boniol M, Pizot C \& Mullie P. Vitamin D status and ill health: a systematic review. Lancet. Diabetes \& Endocrinology 20142 76-89. (doi:10.1016/S2213-8587(13)70165-7)

14 Eastell R, Brandi ML, Costa AG, D'Amour P, Shoback DM \& Thakker RV. Diagnosis of asymptomatic primary hyperparathyroidism: proceedings of the fourth international workshop. Journal of Clinical Endocrinology and Metabolism 201499 3570-3579. (doi:10.1210/jc.2014-1414)
15 Rolighed L, Rejnmark L, Sikjaer T, Heickendorff L, Vestergaard P, Mosekilde L \& Christiansen P. Vitamin D treatment in primary hyperparathyroidism: a randomized placebo controlled trial. Journal of Clinical Endocrinology and Metabolism 201499 1072-1080. (doi:10.1210/ jc.2013-4206)

16 Norenstedt S, Pernow Y, Brismar K, Sääf M, Ekip A, Granath F, Zedenius J \& Nilsson IL. Primary hyperparathyroidism and metabolic risk factors; impact of parathyroidectomy and vitamin D supplementation; results of a randomized double-blind study. European Journal of Endocrinology 2013169 795-804. (doi:10.1530/EJE-13-0547)

17 Norenstedt S, Pernow Y, Zedenius J, Nordenström J, Sääf M, Granath F \& Nilsson IL. Vitamin D supplementation after parathyroidectomy - effect on bone mineral density - a randomized double blind study. Journal of Bone and Mineral Research 201429 960-967. (doi:10.1002/jbmr.2102)

18 Sullivan M \& Karlsson J. The Swedish SF-36 Health Survey III 1998. Evaluation of criterion-based validity: results from normative population. Journal of Clinical Epidemiology 199851 1105-1113. (doi:10.1016/S0895-4356(98)00102-4)

19 Bilezikian JP, Brandi ML, Eastell R, Silverberg SJ, Udelsman R, Marcocci C \& Potts JT Jr. Guidelines for the management of asymptomatic primary hyperparathyroidism: summary statement from the fourth international workshop. Journal of Clinical Endocrinology and Metabolism 201499 3561-3569. (doi:10.1210/jc.2014-1413)

20 IOM (Institute of Medicine). Dietary reference intakes for calcium and vitamin D, pp. 1-113. Washington, DC: The National Academies Press, 2011.

21 Jorde R, Waterloo K, Saleh F, Haug E \& Svartberg J. Neuropsychological function in relation to serum parathyroid hormone and serum 25-hydroxyvitamin D levels: The Tromso study. Journal of Neurology 2006253 464-470. (doi:10.1007/s00415-005-0027-5)

22 Ju SY, Lee YJ \& Jong SN. Serum 25-hydroxyvitamin D levels and the risk of depression: a systematic review and meta-analysis. Journal of Nutrition, Health \& Aging 201317 447-455. (doi:10.1007/s12603-012-0418-0)

23 Ware JE Jr. SF-36 health survey update. Spine 200025 3130-3139. (doi:10.1097/00007632-200012150-00008)

24 Zierold C, Mings JA \& De Luca HF. Regulation of 25 hydroxyvitamin D3-24hydroxylase mRNA by 1,25dihydroxyvitamin D3 and parathyroid hormone. Journal of Cellular Biochemistry $2003 \mathbf{8 8}$ 234-237. (doi:10.1002/jcb.10341)

25 Valcour A, Blocki F, Hawkins DM \& Rao SD. Effects of age and serum 25-OH-vitamin D on serum parathyroid hormone levels. Journal of Clinical Endocrinology and Metabolism 201297 3989-3995. (doi:10.1210/ jc.2012-2276)

26 Mihai R \& Sadler GP. Pasieka's parathyroid symptoms scores correlate with SF-36 scores in patients undergoing surgery for primary hyperparathyroidism. World Journal of Surgery 200832 807-814. (doi:10.1007/s00268-008-9509-9)

Received 18 September 2014

Revised version received 3 November 2014

Accepted 20 November 2014 